\title{
Moving Aerospace Structural Design Practice to a Load and Resistance Factor Approach
}

\author{
Curtis E. Larsen ${ }^{\dagger}$ \\ NASA Langley Research Center, Hampton, Virginia \\ and \\ Ivatury S. Raju \\ NASA Langley Research Center, Hampton, Virginia
}

\begin{abstract}
Aerospace structures are traditionally designed using the factor of safety approach. The limit load on the structure is determined and the structure is then designed for FOS times the limit load - the ultimate load. Probabilistic approaches utilize distributions for loads and strengths. Failures are predicted to occur in the region of intersection of the two distributions. The load and resistance factor design (LRFD) approach judiciously combines these two approaches by intensive calibration studies on loads and strength to result in structures that are efficient and reliable. This paper discusses these three approaches.
\end{abstract}

\section{Introduction}

Load and Resistance Factor Design (LRFD) practices have predominately replaced the use of Allowable Stress (or Strength) Design (ASD) in the design and construction of steel $^{1}$ aluminum $^{2}$, wood ${ }^{3}$, and concrete ${ }^{4}$ structures in commercial and industrial practice ${ }^{5}$ in the U.S and worldwide. These practices characterize the loads to be applied to a structure and specify a load factor to increase that load to its design value depending on the characteristic uncertainty of the load. Similarly, the strength of a structural member is characterized and factored down to a design resistance depending on the characteristics of that member (such as a column vs. a beam). These codes were developed over a number of years by intensive code-calibration studies to result in structural designs that gave approximately the same structural reliability but with less variability as heritage structures yet provided increased economy by increasing the relative resistance of structural members having the greatest uncertainty in performance under load.

Current practice in the aerospace industry is, however, the conventional factor of safety (FOS) approach ${ }^{6-12}$. The practice is to impose on the structure a load case derived to be at some extreme value above nominal such that the load will not be exceeded at some specified probability and confidence. The resulting stress at a critical section of a structural member is computed and a margin of safety is calculated.

In this paper the LRFD practice is compared and contrasted to the aerospace practice, concluding with observations and recommendations for incorporating the best of

\footnotetext{
$\dagger^{\dagger}$ NASA Technical Fellow for Loads and Dynamics, NASA Engineering and Safety Center. Associate Fellow AIAA. ः NASA Technical Fellow for Structures, NASA Engineering and Safety Center. Fellow AIAA, Member ASME, Member ASCE.
} 
the LRFD practice for improving aerospace structural design. First, the conventional FOS and probabilistic approaches as practiced by the aerospace industry is discussed. Next, the LFRD approach and its advantages are presented and compared with the FOS approach.

\section{Conventional Approaches}

Design is the process of making system implementation decisions to meet goals and requirements in the presence of uncertainty. The goals, in general, are range, weight, payload, robustness, reliability, etc. The designs need to satisfy certain requirements such as factors of safety, margin of safety, buckling and crippling loads, fracture control, etc. All designs face uncertainties which can be reducible (knowledge) or irreducible (random). Most of the designs are deterministic, however, probabilistic designs are becoming very popular.

The design process using deterministic analysis methods and tools use input properties and environments that are deterministic or (often) statistically based values (mean-value, 3-sigma, 99/90 specifications, A-basis allowable, etc.) Uncertainties often managed by adding margin or extra capability, (e.g., by using uncertainty factors).

The design process using probabilistic analysis methods and tools use input properties and environments that are specified via probability distributions. Reliability and/or robustness is either a goal or requirement in this approach. Uncertainties are accounted for by physics-based analysis (including model uncertainties). Sensitivities are computed at the failure point, and the sensitivity to the uncertainty parameters are studied in this approach. Quantification of reliability/risk with confidence levels allows reliability and weight/cost trades.

In the remainder of this section the deterministic, probabilistic, and LRFD approaches are discussed

\section{A. Factors of Safety (FOS) Approaches}

To account for uncertainties and unknowns a structural member has been historically designed to carry a load considerably larger than the maximum expected applied load. This design load is established when the maximum expected applied load is multiplied by a FOS. In the 1930's there was ambiguity among the definitions used for design load, expected load and applied loads. Therefore, the U.S. Army Air Corps established the following definitions summarized in Table 1 that are used today in the aerospace industry.

Table 1: Terminology Definitions

Term

Definition 


\begin{tabular}{|l|l|}
\hline Limit Load & $\begin{array}{l}\text { Maximum expected load on the structure in its } \\
\text { lifetime and in the entire fleet. }\end{array}$ \\
\hline Ultimate Load* & $\begin{array}{l}\text { Product of the Limit Load times the Ultimate } \\
\text { Factor of Safety (FOSult). This is the load for } \\
\text { which a structure is designed for ultimate strength } \\
\text { and must be less than the Allowable Ultimate } \\
\text { Load. }\end{array}$ \\
\hline Yield Load & $\begin{array}{l}\text { Product of the Limit Load times the Yield Factor } \\
\text { of Safety (FOSyield). This is a load for which a } \\
\text { structure is designed for yield strength and must } \\
\text { be less than the Allowable Yield Load. }\end{array}$ \\
\hline Allowable Ultimate Load & $\begin{array}{l}\text { The highest load that will not cause material } \\
\text { failure. }\end{array}$ \\
\hline Allowable Yield Load & $\begin{array}{l}\text { The highest load that will not cause material } \\
\text { plastic deformation. }\end{array}$ \\
\hline *Ultimate Load is also often referred to as "Ultimate Design Load" or "Design \\
Ultimate Load".
\end{tabular}

Limit Loads: Limit load as defined above is generally used for all aircraft structures and structural components. The commercial and military aircraft industries base their requirements on the performance required from the appropriate certifying authority. Commercial transport aircraft usually have a design life of 75,000 cycles (take-offs and landings) over 30 years. Military transport aircraft may have similar operational life. Many copies, perhaps thousands of copies, of commercial aircraft are built, while tens to a few hundred copies of military aircraft are built. As such the maximum load that an aircraft structural component may experience is very well defined.

For spacecraft applications, the definitions are slightly different, as environments in spacecraft applications are difficult to characterize; the limit load is simply defined as the maximum anticipated load experienced by a structure during a loading event, load regime, or mission. Uncertainty factors associated with model uncertainty or forcing function uncertainty are usually incorporated into the reported limit load.

Some discussion on the uncertainty factors in early load cycles is warranted here. To reduce design impacts associated with load changes, uncertainty in the load definition shall be accounted for. This uncertainty may be accounted for by incorporating a factor in the results of early load cycles. This factor is used to account for immaturity in models and design, and for changes in launch vehicle models and forcing functions. General practice calls for a minimum factor of 1.5 for the preliminary load cycle. In subsequent load cycles, the factor shall be gradually reduced as the structural design and load 
analysis prediction mature. The uncertainty factor can be eliminated after the structure is built, the model is verified, and the forcing functions are finalized. However, if the model verification is inadequate for some reason, a factor shall be retained in the verification load cycle. The application of uncertainty factors was derived from uncrewed (unmanned) spacecraft practice, but it is empirical, arbitrary, and undoubtedly adds mass to the entire structure that may never be able to be trimmed out. It is simpler add mass as needed to specific components of the structure in subsequent design than to perform mass reduction subsequent to design and fabrication.

Use of an uncertainty factor to account for model variations may be avoided by using sensitivity analysis. Systematic changes are made to potentially uncertain payload properties, and the resulting loads are computed. The design load is taken from the worst case analyzed or from a statistical combination of all cases. Since payload loads are strongly dependent on the frequencies of the payload modes, frequency sensitivity (or "tuning") analysis is a natural technique. By developing design loads that envelop a broad range of frequency shifts (for example, \pm 15 percent), the structural design is capable of handling the load increases that may occur as the design matures. This type of analysis has the advantage of increasing loads only for those items that are sensitive to frequency shifts.

The Factors of Safety for ultimate and yield loads are defined as:

$$
\begin{gathered}
\text { FOS }_{\text {ult }}=\frac{\text { Ultimate Load }}{\text { Limit Load }} \\
\text { FOS }_{\text {yield }}=\frac{\text { Yield Load }}{\text { Limit Load }}
\end{gathered}
$$

In typical aerospace applications, the FOS are requirements based on whether the structure being analyzed is a structure to be test verified or is strictly verified by analyses as well as other risk factors including the brittleness of the structural material, the type of loading, the consequence of failure, etc. (See Reference 8)

\section{Margin of Safety (MOS)}

The aerospace industry also uses an additional term called the Margin of Safety (MOS). The MOS relates the design load to the allowable load.

$$
\begin{aligned}
\operatorname{MOS}_{\text {ult }}= & \frac{\text { Allowable ultimate load }}{\text { Ultimate load }}-1 \\
& =\frac{\text { Allowable ultimate load }}{\text { Limit load } * \text { FOS }_{\text {ult }}}-1
\end{aligned}
$$

and 


$$
\begin{aligned}
\operatorname{MOS}_{\text {yield }} & =\frac{\text { Allowable yield load }}{\text { Yield load }}-1 \\
& =\frac{\text { Allowable yield load }}{\text { Limit load*FOS }_{\text {yield }}}-1
\end{aligned}
$$

When the MOSult equals zero, the Allowable Ultimate Load, or capability, equals the applied Ultimate Load, the load for which the structure was designed. Figure 1 schematically presents the loads defined above and the relationship between FOS ult and

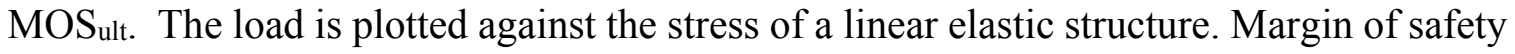
is thus a measure of the remaining load-carrying capacity of a structure existing under an applied load condition. A margin of safety typically serves two functions. First, the algebraic sign of the margin of safety indicates whether or not the structure is safe with respect to the applied loads. Second, the magnitude of the margin of safety indicates the amount the applied loads can be increased without exceeding the stipulated yield or ultimate capability of the structure. Therefore, the analyst must exercise judgment in maintaining some minimum MOS ult to account for part variations, assembly variabilities, and the uncertainties in and limitations of the analyses.

Since the relationship between load and stress is often linear, many engineering texts will define the FOS and MOS with respect to stress as opposed to loads. On the other hand, if a nonlinear relationship between the applied loads and the resulting stresses exists, a margin of safety calculated with respect to the loads, in general, will not be the same as a margin calculated with respect to the stresses. Typical cases are redistribution of loads due to changes in stiffness of the redundant structure, operation in the post-buckled range, and other nonlinear behaviors.

Margin of safety (MOS) on stresses are reported in the analyses using the equation that is similar to the load equation (Eqs. (2) and (3)) as

$$
\text { MOS }=\frac{\text { Allowable stress }}{\text { FOS } \times \text { Calculated stress }}-1
$$

in which the allowable stress is usually developed from uniaxial material testing. The calculated stress is the stress computed using numerical methods such as the finite element (FE) method subjected to the loading condition under consideration. Various loading conditions such as mechanical, thermal, pressure, etc. loads are considered in the FE analyses. The calculated stress could be a maximum principal stress, maximum shear stress, a von Mises stress, etc. depending on the failure scenario that is postulated by the analyst. When dealing with multiaxial stress states, invariant stress measures such as von Mises stresses are usually preferred. While evaluating various failure scenarios, analysts need to evaluate the MOS for each of these scenarios and determine the most constraining scenario and then report the MOS for that scenario. 


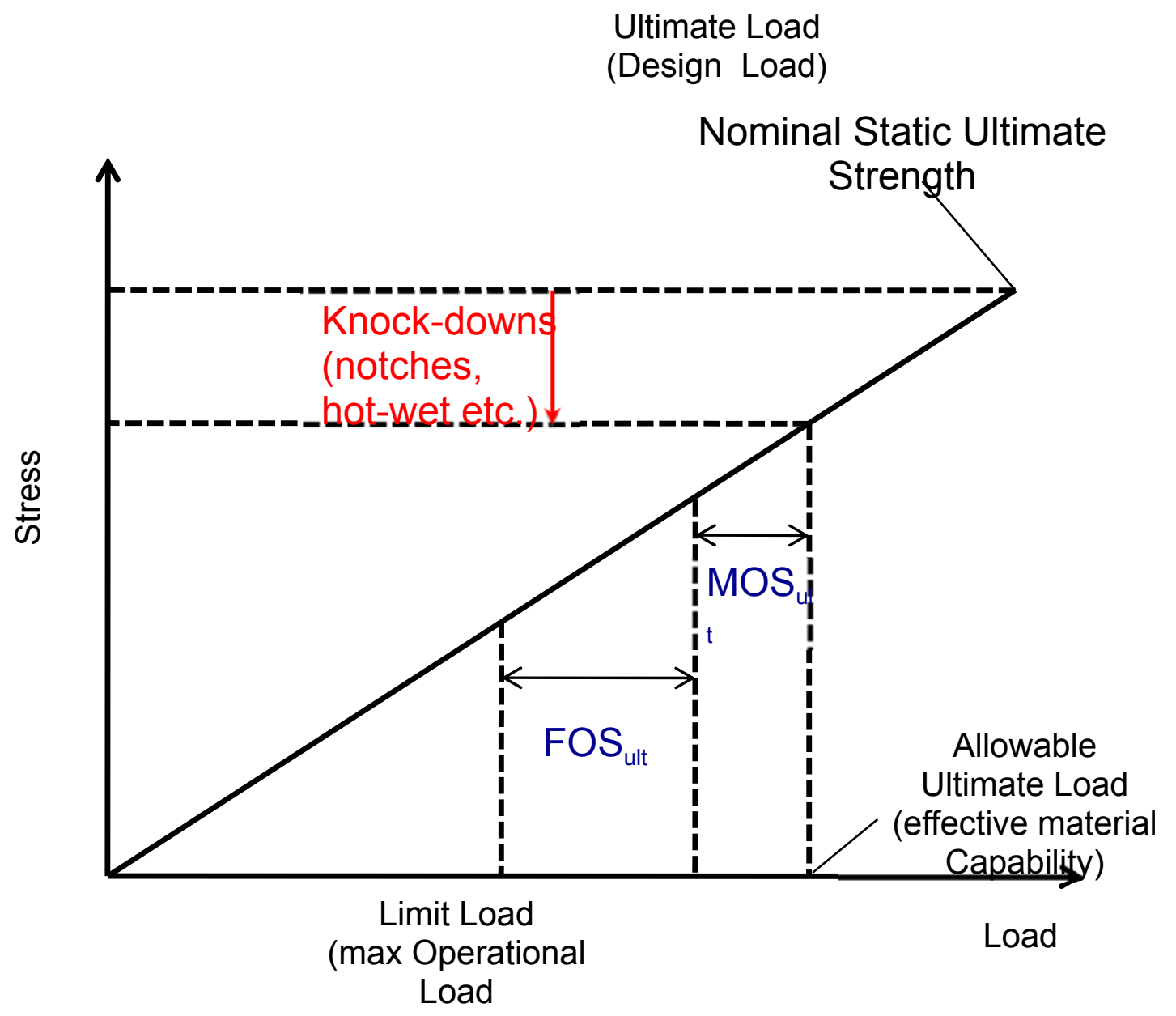


Figure 1. Relationship between factor of safety (FOS) and margin of safety (MOS)

Allowables: As margins depend on strength allowables some discussion on allowables is warranted. Strength allowables are consistent between the aircraft and spacecraft applications. Both aircraft and spacecraft standards require that strength allowables should properly account for the effects of environment (e.g., temperature, humidity, vacuum, chemicals), but beyond that they do not specify which properties (e.g., notched or unnotched strength) should be used for design allowables.

Strength allowable values are generated typically using uniaxial tests performed at different environmental conditions (e.g., different values of temperature, humidity). These values are usually from load-to-failure tests with maximum load ('stress') and strain-at-failure recorded. For composite systems exhibiting a nonlinear response, repeated loading-unloading cycles with increasing load level may provide insight into the overall material response (i.e., nonlinear elastic or damage accumulation).

The definition of statistical sampling and data reduction methods for what constitutes an A- or B-basis for strength allowables is common among the aircraft and spacecraft design standards. Also common is the general requirement that B-basis design allowables will be used for a redundant or fail-safe structure and A-basis design allowables will be used for a single load path structure. A redundant or fail safe structure is defined as follows: A structural design criterion in which it must be shown that the structure remaining, after failure of any single structural member, can withstand the resulting redistributed internal limit loads without failure. Hence, a fail-safe design has the ability to sustain a failure and retain the capability to safely terminate or control the operation. Thus, redundant failsafe structural designs are desirable. In fact, space vehicle fail-safe structural designs using B-basis strength allowables are used by the current NASA [8-11] and European Space Agency (ESA) requirements [12-14].

The manufacturing processes are highly specialized and monitored by suppliers through extensive testing of company designs of materials, coupons, joints, components, and structural elements. As a result of this comprehensive testing, an extensive database of material properties and structural performance data is created for each system. The aircraft are certified to meet applicable requirements based on detailed reviews that ensure that the aircraft meet safety and performance criteria for the fleet mission environments and loadings, which are usually well defined [15-17] and can be incorporated in the certification test programs. In contrast, space vehicle missions typically have no or very limited opportunities to inspect, repair, or modify the structure once they lift off from the launch pad. This is a major and fundamental difference between the aircraft approach and the spacecraft approach to composite structural design methodology. While the aircraft in-service inspection/repair approach could be adopted for any space vehicle that returns periodically to Earth, it would require the space vehicle program to develop and certify capabilities similar to those in use for aircraft while addressing the more challenging aspects of missions that operate in space environments. 
There are some examples within the NASA Space Shuttle Program where refurbishment of vehicle components was performed, but this practice is not common because of the risks of damage to expensive space-qualified vehicles. Instead, spacecraft structures are typically designed for a single launch, the operating environment is not well quantified, and are certified to perform their entire mission without interim inspections or repairs to reduce operational costs.

\section{B. Probabilistic approaches:}

The basic probabilistic approach can be summarized as the quantification of all input data, model equations, and the output in a statistical manner. Figure 2 compares the deterministic and probabilistic approaches. This requires the use of a statistical procedures to take the model equations and input data and produce a statistical /probabilistic output. These techniques range from pure Monte Carlo to integral solutions. Figure 3 illustrates this process. The left-hand side of the figure shows all of the input data, indicating a statistical distribution for each. The right-hand side illustrates the various capabilities of the structure, and the middle shows the output of the process in a statistical sense.
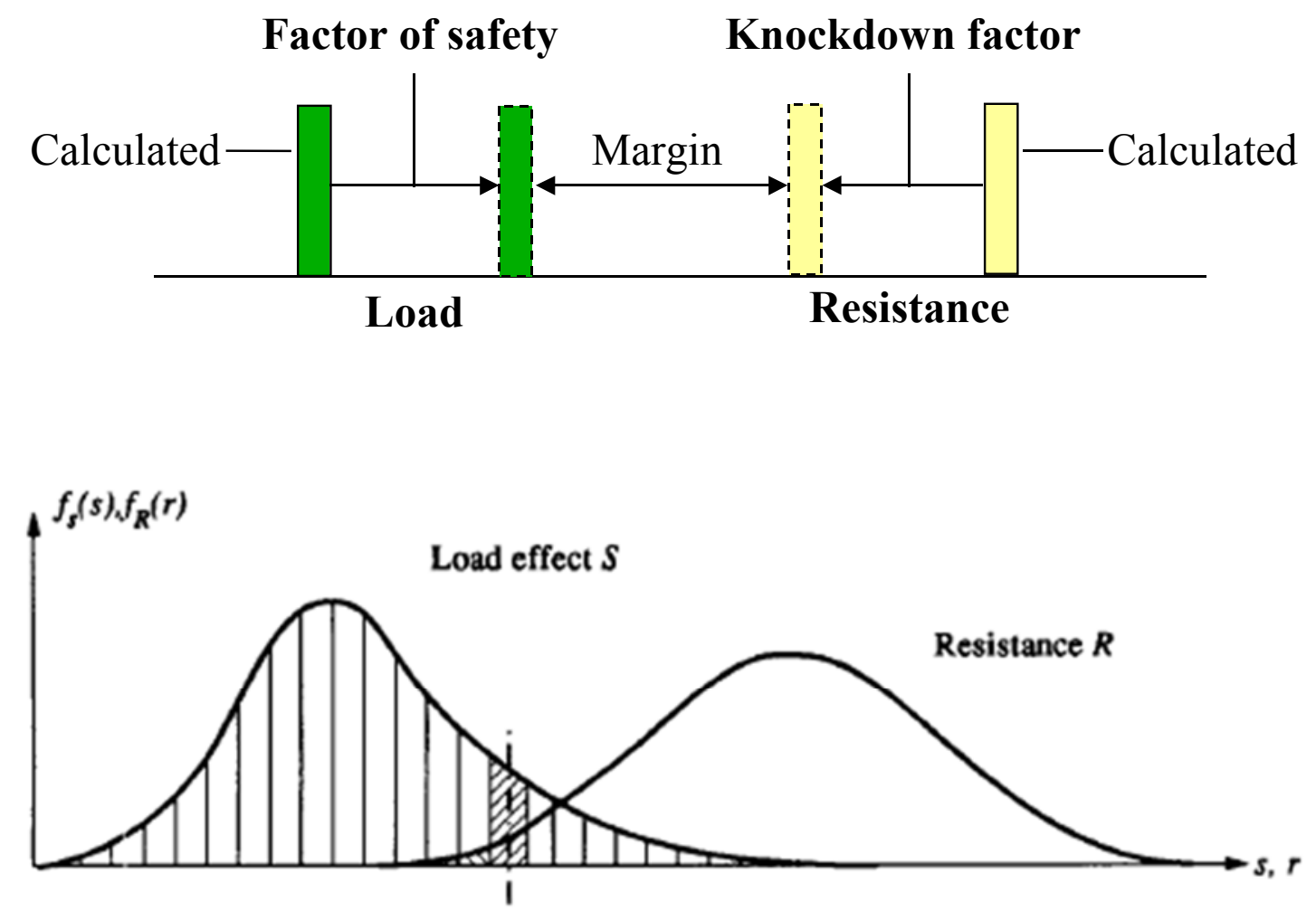
Figure 2. Traditional FOS and Probabilistic approaches

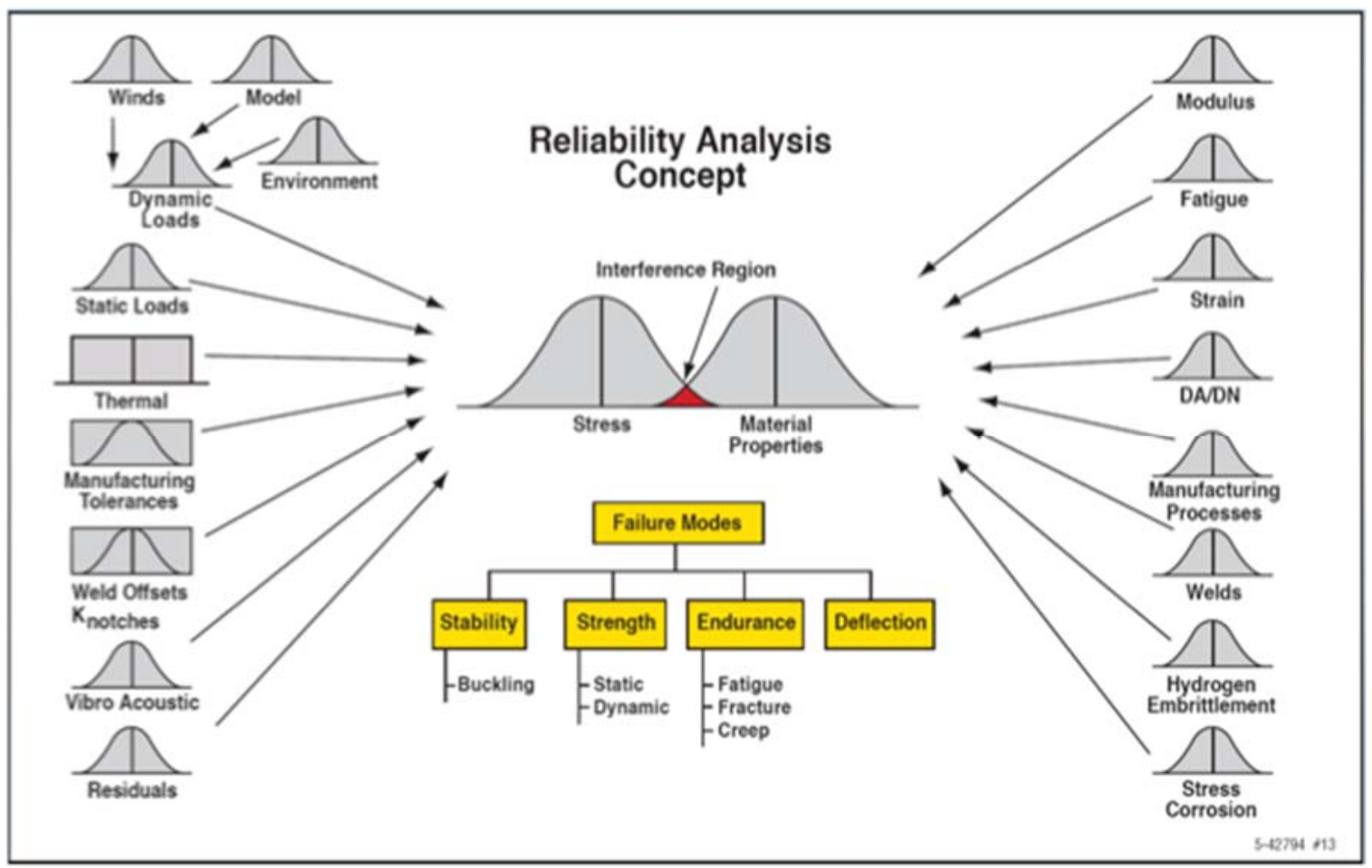

Figure 3. Probabilistic analysis concept ${ }^{\S}$

\section{LRFD}

In the Load and Resistance Factor Design (LRFD) method, also known as limit state design, a structure is sized to take into account the inherent uncertainties of the resistances and the load effects in a consistent way to yield a target reliability. A limit state is a condition of a structure beyond which it no longer fulfills the relevant design criteria. The condition may refer to a degree of loading or other actions on the structure, while the criteria refer to structural integrity, fitness for use, durability or other design requirements. A structure designed by LRFD is proportioned to sustain all actions likely to occur during its design life, and to remain fit for use, with an appropriate level

$\S$ Figure taken from R. Ryan's course material (reproduced here with permission) 
of reliability for each limit state. Building codes based on LRFD implicitly define the appropriate levels of reliability by their prescriptions.

The limit state is a computational requirement/condition that must be fulfilled in order to comply with the engineering demands for strength and stability under design loads. The limit state condition is computationally evaluated at a certain point along the behavior function of the structural scheme, located at the upper part of its elastic zone at approximately $15 \%$ lower than the elastic limit. That means that the limit state is a purely elastic condition, located on the behavior function far below the real ultimate point, which is within the plastic zone. The rationale for choosing the limit state at the upper part of the elastic zone is that as long as the LRFD criteria are fulfilled, the structure will behave in the same way under repetitive loadings, and as long as it keeps this way, it proves that the level of safety and reliability assumed as the basis for this design is properly maintained and justified. A structure is deemed to satisfy the ultimate limit state criterion if all factored bending, shear and tensile or compressive stresses are below the factored resistances calculated for the section under consideration. The factored stresses referred to are found by applying Magnification Factors to the loads on the section. Reduction Factors are applied to determine the various factored resistances of the section. The limit state criteria can also be set in terms of load rather than stress: using this approach the structural element being analyzed (i.e.,. a beam or a column or other load bearing element, such as walls) is shown to be safe when the "Magnified" loads are less than the relevant "Reduced" resistances.

Complying with the design criteria of the LRFD is considered as the minimum requirement (among other additional demands) to provide the proper structural safety. The load and resistance factors are determined using statistics and a pre-selected probability of failure. Variability in the quality of construction, consistency of the construction material are accounted for in the factors. Generally, a factor of unity (one) or less is applied to the resistances of the material, and a factor of unity or greater to the loads. Not often used, but in some load cases a factor may be less than unity due to a reduced probability of the combined loads. These factors can differ significantly for different materials or even between differing grades of the same material. Wood and masonry typically have smaller factors than concrete, which in turn has smaller factors than steel. The factors applied to resistance also account for the degree of scientific confidence in the derivation of the values (i.e. smaller values are used when there isn't much research on the specific type of failure mode). Factors associated with loads are normally independent on the type of material involved, but can be influenced by the type of construction.

The simplest expression of the LRFD criterion is given by the general formula ${ }^{18}$ 
$\varphi R_{n} \geq \gamma_{k} Q_{k m}$

in which $R_{n}$ is the nominal resistance computed according to a structural code and based on nominal material and cross-sectional properties, which may include interaction equations, $\phi$ is the resistance factor, always less than unity, which together with $R_{n}$ reflects the uncertainties associated with $R . \quad \gamma_{k}$ is the load factor, always greater than or equal to unity, which together with $Q_{k m}$ reflects the uncertainties associates with $Q$.

Limit state design was originally based on research by Professor N.S. Streletzki and introduced to the building regulations of the USSR ${ }^{27}$. In the United States the building, highway, railroad, and offshore industries have adopted limit state design or LRFD for concrete $^{4}$, steel ${ }^{1,5,28,29,37}$, aluminum ${ }^{2}$, fiber reinforced plastic ${ }^{30}$ and timber ${ }^{3}$ building, bridge and tower structures.

For example, the steel construction manual ${ }^{1}$ specifies the following:

Tension Members; tensile yield in gross section: $\phi=0.90$

Tension Members; rupture in net section: $\phi=0.75$

Compression members; for flexural, torsional, or flexural-torsional buckling: $\phi=0.90$

Flexural members: $\phi=0.90$

Shear: $\phi=0.90$

For buildings, nominal loads, load factors and load combinations are specified in ASCE/SEI 7, Minimum Loads for Buildings and Other Structures ${ }^{31}$. For example, basic combinations of factored loads are provided for dead load (D), earthquake load (E), live (floor) load (L), roof load (Lr), rain load, snow load, and wind load (W) as:

1. $1.4 \mathrm{D}$

2. $1.2 \mathrm{D}+1.6 \mathrm{~L}+0.5(\mathrm{Lr}$ or $\mathrm{S}$ or $\mathrm{R})$

3. $1.2 \mathrm{D}+1.6(\mathrm{~L}$ or $\mathrm{S}$ or $\mathrm{R})+(\mathrm{L}$ or $0.5 \mathrm{~W})$

4. $1.2 \mathrm{D}+1.0 \mathrm{~W}+\mathrm{L}+0.5(\mathrm{Lr}$ or $\mathrm{S}$ or $\mathrm{R})$

5. $1.2 \mathrm{D}+1.0 \mathrm{E}+\mathrm{L}+0.2 \mathrm{~S}$

6. $0.9 \mathrm{D}+1.0 \mathrm{~W}$

7. $0.9 \mathrm{D}+1.0 \mathrm{E}$

The load magnification factors and resistance reduction factors were determined by the process of code calibration in which all the parameters specified by the design code are selected to give a desired reliability spectrum as judged by assessment of experience with the existing (assumed successfully safe and economical) code practice ${ }^{26}$. Details of this effort for the design of steel structures in the US are provided in Refs. 19-21. Key to this 
process was the use of a first-order probabilistic design method, and the use of the "safety or reliability index" $\beta$, which gives a relative measure of reliability in terms of the mean values of resistance and load, $R_{m}$ and $Q_{m}$, and the corresponding coefficients of variation, $V_{R}$ and $V_{Q}$ :

$$
\beta=\ln \left(\mathrm{R}_{m} / Q_{m}\right) / \sqrt{\left(V_{R}^{2}+V_{Q}^{2}\right)}
$$

It was concluded from the calibration that $\beta=3.0$ and $\beta=4.5$ were selected for members and connectors, respectively. It is also of interest as an illustration for aerospace applications that the civil structural design process includes a failure risk and consequence categorization of structures, and provides an acceptable reliability (or maximum annual probability of failure) and associated reliability index $\beta$ as shown in Table $1^{31}$.

\begin{tabular}{|c|c|c|c|c|}
\hline \multirow[b]{2}{*}{ Basis } & \multicolumn{4}{|c|}{ Risk Category } \\
\hline & I & ॥ & III & IV \\
\hline $\begin{array}{l}\text { Failure that is not sudden and does not lead to widespread } \\
\text { progression of damage }\end{array}$ & $\begin{aligned} P_{F} & =1.25 \times 10^{-4} / \mathrm{yr} \\
\beta & =2.5\end{aligned}$ & $\begin{aligned} P_{F} & =3.0 \times 10^{-5} / \mathrm{yr} \\
\beta & =3.0\end{aligned}$ & $\begin{aligned} P_{F} & =1.25 \times 10^{-5} / \mathrm{yr} \\
\beta & =3.25\end{aligned}$ & $\begin{aligned} P_{F} & =5.0 \times 10^{-6} / \mathrm{yr} \\
\beta & =3.5\end{aligned}$ \\
\hline $\begin{array}{l}\text { Failure that is either sudden or leads to widespread } \\
\text { progression of damage }\end{array}$ & $\begin{aligned} P_{F} & =3.0 \times 10^{-5} / \mathrm{yr} \\
\beta & =3.0\end{aligned}$ & $\begin{aligned} P_{F} & =5.0 \times 10^{-6} / \mathrm{yr} \\
\beta & =3.5\end{aligned}$ & $\begin{aligned} P_{F} & =2.0 \times 10^{-6} / \mathrm{yr} \\
\beta & =3.75\end{aligned}$ & $\begin{aligned} P_{F} & =7.0 \times 10^{-7} / \mathrm{yr} \\
\beta & =4.0\end{aligned}$ \\
\hline $\begin{array}{l}\text { Failure that is sudden and results in widespread progression } \\
\text { of damage }\end{array}$ & $\begin{aligned} P_{F} & =5.0 \times 10^{-6} / \mathrm{yr} \\
\beta & =3.5\end{aligned}$ & $\begin{aligned} P_{F} & =7.0 \times 10^{-7} / \mathrm{yr} \\
\beta & =4.0\end{aligned}$ & $\begin{aligned} P_{F} & =2.5 \times 10^{-7} / \mathrm{yr} \\
\beta & =4.25\end{aligned}$ & $\begin{aligned} P_{F} & =1.0 \times 10^{-7} / \mathrm{yr} \\
\beta & =4.5\end{aligned}$ \\
\hline
\end{tabular}

Table $1^{* *}$. Acceptable Civil Structural Reliability

Maximum annual probability of failures, $P_{f}$, range from $P_{f}=1.25 \times 10^{-4} /$ year and $\beta=2.5$ (for a 50-year service period) for structures that represent low risk to human life and do not fail suddenly or with widespread progression of damage; to $P_{f}=1.0 \times 10-7$ and $\beta=$ 4.5 for structures designated as essential facilities or the failure of which could pose a substantial hazard to the community.

This development is of interest to the aerospace structures community because only recently have spacecraft design requirements begun to be cast in terms of the risk of failure or probability of success ${ }^{32,33}$. Most often the aerospace usage for human-rated spacecraft has been to develop the applied forcing functions and resulting load responses in a probabilistic manner (setting the limit load at the so-called "3-sigma" level), but then the design proceeds in a deterministic manner with the application of the FOS. The exception is the material strength which has typically been treated in a statistical manner using A- or B-basis allowables. However, no NASA requirements have been set forward for a target reliability against structural failure.

${ }^{* *}$ Table excerpted from Ref. 31 (reproduced with permission). 


\section{Discussion}

Exploring in more detail the typical space vehicle design practice, it is observed that liftoff response loads are most often developed from Monte Carlo simulations of the transient dynamic event, allowing explicitly the determination of 99.87-percentile loads with a specified confidence (or 99 percentile with $90 \%$ confidence for unmanned vehicles). Response loads for ascent flight events such as transonic, maximum buffet, or maximum dynamic pressure, now most often follow a load combination equation approach as developed in Refs. 34 and 35. This is a statistical load combination approach, based on a series of approximations implemented as either a root-sum-squared combination, a central limit theorem combination, or an envelope function combination equation. This load combination approach was originally intended to reduce the computational burden for time-critical day-of-launch analyses as compared to a Monte Carlo combination of computed response time histories, or Monte Carlo draws from appropriate load distributions. However, this load combination approach has also found apparently wide acceptance in design practice, such as with NASA's Space Launch System (SLS) and Orion Multi-Purpose Crew Vehicle (MPCV) Programs ${ }^{36}$.

To date, the single FOS application to the statistically developed loads has been the norm in practice, except perhaps for a special case in the Space Shuttle Program. In development of the lightweight external tank (LWT), 6000 of pounds of dry weight were shaved from the structure, in part by declaring some loads as "highly predictable quasistatic loads" such as steady thrust, inertial loads from steady acceleration, and weight ${ }^{22}$. A combination equation was used to determine a "combined FOS" that was then applied to the total load 22 :

\section{Combined FOS $=[(\%$ Quasi-Static $) / 100 \%] 1.25+[(\%$ Not Quasi- Static) $/ 100 \%] 1.4$}

The combined FOS was restricted to use only for ascent quasi-static loads in the range of $75 \%$ to $100 \%$ of the total load, and thus the combined factor of safety could range from 1.25 to 1.29 . Otherwise the nominal FOS $=1.4$ was required. This was a step in the direction of applying an LRFD approach by recognizing a different FOS for cases in which some of the contributors to the total load were better known than other portions of the total load.

Implementing an LRFD approach in aerospace practice will require a calibration effort as described in Ref. 26 to assign the parameters in the proposed design code. Note that this will require the aerospace community, or the appropriate customer or regulatory body (e.g. NASA or the FAA), to set a goal for the desired level of reliability in error free structures. Code calibration may then proceed by a formal process of explicit optimization in five steps. 
The first step defines the scope or class of parameterized structures for which the code is applicable. A class of relevant failure modes for these structures is also defined. The second step defines the code objective, such as a target reliability or acceptable probability of failure with a specified acceptable variability over the code parameter data set.

Determination of the frequency of occurrence of the most important safety check is the third step. Because the code cannot in general exactly meet the objective and be at the same time simple, it is necessary to define the particular safety check for which the objective is to be met as closely as possible. The fourth step is to select a measure of closeness between the objective and a code realization for use in the optimization. For example, Ref. 26 suggests that the target value of the reliability index in a particular safety check, $\beta^{*}$, and the actual value $\beta$ generated by the safety check, could be used as a closeness criterion such that $E\left[\left(\beta^{*}-\beta\right)^{2}\right]$ not exceed a given value.

Finally, a sequence of trial code formats is selected in order of increasing complexity, the goal being to seek the simplest code format that meets the objective criterion. Ref. 26 lists a number of civil structural design codes that have been developed using code optimization and provide specific examples related to the Nordic Committee on Building Regulations calibration. This process in non-trivial and takes considerable investment, seven years of research as noted by Ref. 18 for steel buildings, and anecdotally a decade for steel offshore platforms ${ }^{37}$.

One advantage of moving to an LRFD design approach over implementing a fully probabilistic design methodology is in the advantage of everyday application of a simpler, more familiar format (factored-up loads and "knocked-down" capabilities) by engineers specializing in the intricacies structural engineering, vs. the complexity of applying to every design the available methods of structural reliability, which may be argued require yet another level of sophistication by practicing engineers in what some view are the arcane arts of applied statistics and probability. The timeliness of the design process by LRFD vs. a fully probabilistic approach is yet another advantage, as the current design cycle turnaround time is already becoming unwieldy and uneconomical, witness the millions of degrees of freedom in our stress and dynamic finite element models, and the tens of thousands of recovery items in our coupled loads analysis output transformation matrices. Additionally, moving to LRFD can be viewed as an informative, educational incremental step in the transformation of the design process, perhaps eventually to a fully probabilistic approach for at least selected high value problems.

Finally, one may observe that current aerospace structural design practice is nearly an LRFD process as it is. As previously discussed, limit loads are developed to a specified or implied envelope probability ( $99 \%$ with $90 \%$ confidence, or 99.875 at $50 \%$ confidence) commonly using a load combination equation, and may be factored to account either by judgment or sensitivity analysis for inevitable dynamic model changes as the design matures. On at least one documented occasion the factor of safety was 
adjusted to account for the uncertainty of the loads and rigor of certification ${ }^{22}$. On the strength side, current practice is to use A- or B-basis allowables, and various factors for joints, discontinuities, buckling, etc. to reduce the design capacity of the structure for margin checking. The advantage that an LRFD calibration would afford is that of making a rationale selection of the many parameters involved in the design process to better balance the relative risk of failure by the various limit states, and of moving the mass of the structure to better resist the more uncertain and critical failure modes.

A parting illustration on the resistance to change demonstrated by our discipline may be had by careful reading of Ref. 38, published in 1977, and noting how much of what the authors reported then with respect to the state of the art and future outlook of the application of factors of safety and structural reliability methods is unchanged and still applicable to our practice today, some 38 years later. Perhaps it's time to move on.

\section{Concluding Remarks}

Aerospace structures are traditionally designed using the factor of safety approach. The practice is to impose on the structure a load case derived from an extreme value - the limit load. The structure is then designed for FOS times the limit load - the ultimate load. Probabilistic approaches utilize distributions for loads and strengths and determine the probability of failure when these distributions intersect. The load and resistance factor design (LRFD) approach judiciously combines these two approaches by intensive calibration studies on loads and strength to result in structures that are efficient and reliable. The LRFD is pioneered by civil engineering community and the aerospace engineers should study and adopt this approach for aerospace structures.

\section{References:}

1. Anonymous, AISC Steel Construction Manual, $14^{\text {th }}$ Ed., 2011.

2. Anonymous, Aluminum Design Manual, 10 ${ }^{\text {th }}$ Ed., 2015.

3. Anonymous, ASD/LRFD Manual for Engineered Wood Construction, National Design Specification for Wood Construction, 2012 Ed., American Wood Council.

4. Anonymous, ACI-318-14 Building Code Requirements for Structural Concrete and Commentary, American Concrete Institute, 2014.

5. Anonymous, ISO 19902:2007, Petroleum and Natural Gas Industries - Fixed Steel Offshore Structures

6. Bruhn, E. F., Analysis and Design of Flight Vehicle Structures, Jacobs Publishing, Inc., 1973.

7. Anonymous, Astronautics Structures Manuals - Volume 1-3, NASA TMX73305-73307, August 1975. 
8. Anonymous, NASA-STD-5001B, Structural Design and Test Factors of Safety for Spaceflight Hardware, August 6, 2013. (NASA-STD-5001 (1996) and 5001A (2008) were the original and revised versions, respectively)

9. K. S. Bernstein, Structural Design Requirements and factors of safety for spaceflight hardware for human space flight, JSC 6582, Rev A, October 2011.

10. Anonymous, NASA-STD-5019, Fracture Control Requirements for Spaceflight Hardware. July 2008.

11. Anonymous, MSFC-RQMT-3479, EM 20, Multiprogram/project common-use document, Fracture Control Requirements for Composite and Bonded Vehicle and Payload Structures. May 2006.

12. Anonymous, ECSS-E-ST-32C, Rev. 1, Space Engineering - Structural General Requirements. November 2008.

13. Anonymous, ECSS-E-32-10C-Rev. 1, Space Engineering - Structural Factors of Safety for Space Flight Hardware. March 2009.

14. Anonymous, ECSS-E-32-01C, Rev. 1, Space Engineering - Fracture Control. March 2009.

15. Anonymous, Department of Defense Joint Service Specification Guide Aircraft Structures. JSSG-2006, 30 October 1998.

16. Anonymous, MIL-HDBK-17-3F, Department of Defense Handbook, Composite Materials Handbook, Volume 3, Polymer Matrix Composites Materials Usage, Design, and Analysis, Chapter 7, Damage Resistance, Durability, and Damage Tolerance. 17 June 2002.

17. Anonymous, CMH-17-3G, Working Draft Rev. G, Composite Materials Handbook, Volume 3, Polymer Matrix Composites Materials Usage, Design, and Analysis. Under review, publication anticipated in 2011.

18. M. K. Ravindara and T. V. Galambos, The load and resistance factor design for steel”, Journal of Structural Engineering, ASCE, Vol. 104, ST 9, September 1978, pp, 1337-1353.

19. T. V. Galambos, B. Ellingwood, J. G. MacGregor, and C. A. Cornell, "Probability Based Load Criteria: Assessment of Current Design Practice", Journal of Structures Division, ASCE, Vol. 108, May 1982, pp. 959-977.

20. B. Ellingwood, J. G. MacGregor, T. V. Galambos, and C. A. Cornell, "Probability Based Load Criterion: Load Factors and Load Combinations", Journal of Structures Division, ASCE, Vol. 108, May 1982, pp. 978-997.

21. F. M. Bartlett, R, J, Dexter, M. D. Graeser, J. J. Jelinek, B. J. Schmidt, and T. V. Galambos, "Updating Standard shape material properties database for design and reliability”, Engineering Journal, First Quarter 2003, pp. 2-14

22. Anonymous, NSTS 07700, Volume X, Books 1-6 (specifically Book 1, section 3.2.2.1.5 for structure), November 10, 1998.

23. Anonymous, NASA-STD-5002, Loads Analyses of Spacecraft and Payloads, June 21, 1996.

24. Anonymous, , NASA-STD-5005, Design Criteria Requirements for Payloads Using the Space Shuttle, September 15, 2003. 
25. G. E. Muller and S. J. Clement, "Factor of Safety - USAF Design Practice", Air force Flight Dynamics Lab Wright Paterson AFB, April 1978.

26. H. E. Madsen, S. Krenk, and N. C. Lind, Methods of Structural Safety, PrenticeHall, 1986.

27. N.S. Streletzki. Statistical basis for the evaluation of the structural safety factor. Stroizdat, Moscow: State Publishing House for Buildings, 1947.

28. Anonymous, AASHTO LRFD Bridge Design Specifications, $6^{\text {th }}$ Ed., 2012.

29. Anonymous, AREMA Manual for Railway Engineering, 2015.

30. R. E. Chambers, "ASCE Design Standard for Pultruded Fiber-Reinforced-Plastic (FRP) Structures", Journal of Composites for Construction, Vol. 1, No. 1, February 1997, pp. 26-38.

31. Anonymous, "Minimum Design Loads for Buildings and Other Structures", ASCE/SEI 7-10, 2013.

32. Anonymous, CxP 70070, Constellation Program Management Plan.

33. Anonymous, MPCV 70017, Orion Multi-Purpose Crew Vehicle Program (MPCV) Probabilistic Risk Assessment (PRA) Requirements Document.

34. H. Sako, A. M. Kabe, and S. S. Lee, "Statistical Combination of Time-Varying Loads", AIAA Journal, Vol. 47, No. 10, October 2009.

35. A. M. Kabe et al., "Launch Vehicle Atmospheric Flight Loads", Journal of Spacecraft and Rockets, Vol. 37, No. 4, July-August 2000.

36. Anonymous, SLS-PLAN-062, Space Launch System Program (SLSP) Integrated Vehicle Loads Control Plan, May 2013.

37. Anonymous, API RP 2A-LRFD, Recommended Practice for Planning, Designing and Constructing Fixed Offshore Platforms - Load and Resistance Factor Design, 1st Edition, July 1, 1993.

38. R.J. Meyer-Jens et al., Factors of Safety: Historical Development, State of the Art and Future Outlook, AGARD Report No. 661, November 1977. 